
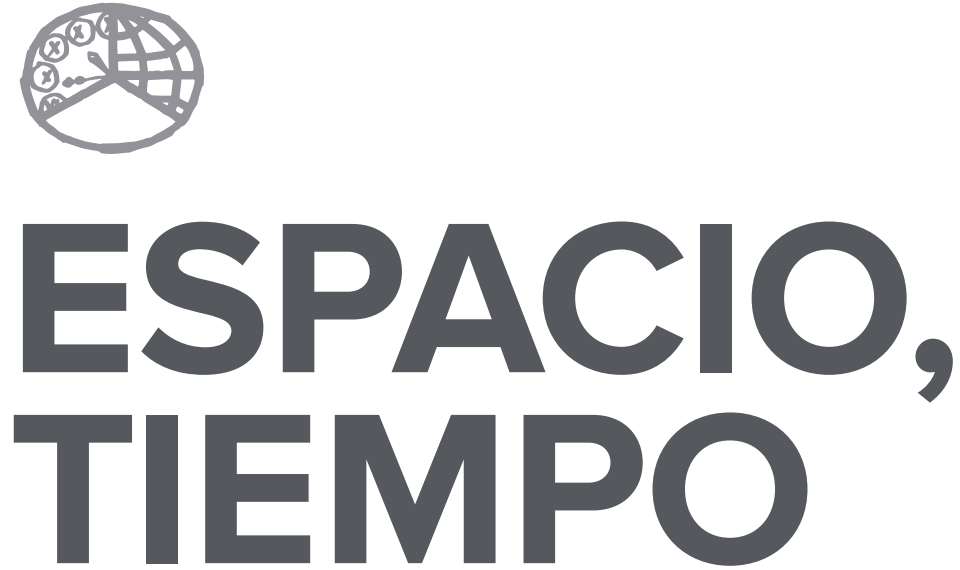

AÑO 2020

ISSN 0214-9745

E-ISSN 2340-1362
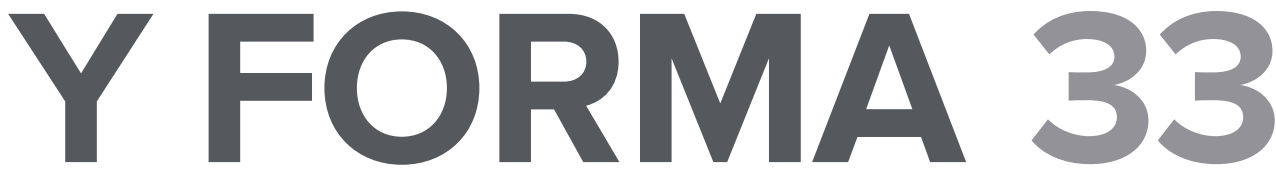

SERIE III HISTORIA MEDIEVAL

REVISTA DE LA FACULTAD DE GEOGRAFÍA E HISTORIA 



\section{ARTÍCULOS · ARTICLES}





\title{
EL MANTENIMIENTO DEL \\ ENTRAMADO VIARIO ROMANO \\ EN ÉPOCA MEDIEVAL EN LA RIOJA. \\ ALGUNOS CASOS DE ESTUDIO
}

\section{THE SURVIVAL OF THE ROMAN ROAD NETWORK IN MEDIEVAL TIMES IN LA RIOJA. SEVERAL CASE STUDIES}

\author{
Adrián Calonge Miranda ${ }^{1}$ \\ Recepción: 2019/09/08 · Comunicación de observaciones de evaluadores: 2019/11/19 . \\ Aceptación: 2020/01/07
}

DOI: http://dx.doi.org/10.5944/etfiii.33.2020.25532

\section{Resumen}

Con la caída política del Imperio Romano de Occidente en el año 476, su entramado viario siguió en servicio y constituyó una de las principales bases económicas y militares de los diferentes poderes que fueron surgiendo. Tomando como ejemplo el valle medio del Ebro (La Rioja y las provincias de Burgos y Álava), se van a estudiar tres calzadas de origen romano que siguieron en uso durante la Edad Media. Así mismo, con el estudio del patrón de asentamiento de las iglesias, las fortalezas con centros religiosos y el hábitat en cuevas, se va a reforzar la tesis de la pervivencia de las calzadas romanas en la región. Para ello se han utilizado fuentes documentales medievales e información procedente de la arqueología.

\section{Palabras clave}

Vías romanas; cristianismo; comercio; Edad Media; pervivencia.

\section{Abstract}

Since the fall of the Western Roman Empire in 476, its network of roadways remained in service and became one of the main economic and military pillars of the different powers that were born of it. Focussing on the geographical area

1. Universidad del País Vasco/Euskal Herriko Unibertsitatea. C.e.: adrian.calonge@ehu.eus 
of the Middle Ebro valley (La Rioja and part of the provinces of Burgos and Alava) we will study three roadways of Roman origin that continued in use throughout the Middle Ages. By studying the settlement pattern of churches, fortresses with religious centres, and cave dwellings, we may strengthen the theory of the survival of Roman roadways in the region. For this purpose, medieval documentary sources and data provided by archeology will be used.

\section{Keywords}

Roman Roadways; Christianity; Trade; Middle Ages; Survival. 


\section{INTRODUCCIÓN}

Una de las grandes herencias que Roma dejó en todo su imperio fue la construcción y el mantenimiento de una tupida red de calzadas que servían para poder controlar y vertebrar el territorio, aportaban una gran infraestructura militar para el rápido transporte de tropas y suministros, y se terminaron convirtiendo en una de las bases económicas más importantes para las provincias, haciendo florecer el comercio.

La caída del poder político imperial y su sustitución paulatina por la monarquía visigoda, que se acabaría asentando en la Península Ibérica no significó una ruptura con los modos de vida de origen romano ni el abandono de las infraestructuras. El caso de la villa romana de Parpalinas prueba la supervivencia de los primeros, mientras que el uso del entramado viario en los siglos altomedievales prueba lo segundo. De esta manera, se va a proceder al estudio de tres calzadas de origen romano y la geografía de las edificaciones cristianas para poder demostrar la supervivencia de las vías antiguas hasta el año ıooo.

Para ello se han utilizado los datos arqueológicos, toponímicos y documentales, especialmente los recogidos en los cartularios medievales que recopilaban las propiedades de los grandes centros religiosos como San Millán de la Cogolla, San Martín de Albelda, Nuestra Señora de Valvanera o Santa María La Real de Nájera. Así mismo, el estudio de los recintos fortificados que surgieron a partir del siglo $\mathrm{V}$ en la periferia del territorio de las antiguas ciudades y su control directo del entramado viario o el desarrollo de los conjuntos rupestres de carácter civil, militar y eremítico que fueron surgiendo a partir de finales de la cuarta centuria de nuestra Era y que siguen desde los puntos altos los diferentes trazados viarios, refuerzan ese uso continuado de la infraestructura de calzadas desarrollada por el antiguo poder romano.

\section{VİAS ROMANAS QUE CONTINUARON EN USO}

\section{II.1. LA CALZADA DEL EBRO}

Esta vía es una de las principales construidas en época romana y aprovechaba el valle del Ebro como entrada natural desde la costa levantina para poder acabar en la rica región del noroeste ${ }^{2}$ y era la más importante de las calzadas que atrave-

2. Recogida en el Itinerario de Antonino. La calzada del Ebro se encuentra plasmada en dos vías: la 1 De Italia in Hispanias (Itin. Ant. 387.4-395.4) y la 32 Ab Asturica Terracone (Itin. Ant. 448.2-452.5). 
saban La Rioja ${ }^{3}$ siendo, además, la única que conserva testimonios epigráficos de intervención imperial en varios miliarios ${ }^{4}$.

Tal y como se ha investigado en otras zonas, como la vecina provincia de Burgos, parte del entramado viario recogido en el Itinerario de Antonino se puede rastrear gracias a las menciones recogidas en la documentación de época medieval, especialmente bajo los términos calzata, strata o via pública ${ }^{5}$. En el caso de la calzada De Italia in Hispanias en su tramo riojano, especialmente en el entorno de Nájera.

La ciudad najerense acabó heredando la preeminencia demográfica, política, social y religiosa que antaño tuvo la antigua civitas tritiense. En el conjunto documental de Santa María La Real se guardaron dos testimonios del paso de esta arteria viaria en Nájera y en Hormilla en un documento donde se mencionaban las propiedades del Monasterio ${ }^{6}$. En el Becerro Galicano de San Millán de la Cogolla, en un intercambio de propiedades entre el cenobio emilianense y el de Santa Coloma, se menciona la calzada entre Tricio y Nájera ${ }^{7}$ y se puede rastrear más hacia el oeste en Alesoncillo ${ }^{8}$, Castañares ${ }^{9}$ y el entorno de Grañón ${ }^{\text {Io }}$.

El comercio y el transporte de mercancías también pueden ofrecer pruebas de la utilización de las calzadas del Itinerario de Antonino en época medieval. Para ello hay que hablar de una villa romana investigada por el profesor Urbano Espinosa en el término de Parpalinas (Ocón, La Rioja). Se trata de una explotación donde se exhumaron los restos de una domus, una planta de procesamiento de vino, indicios de un alfar, un trujal para la elaboración de aceite, una iglesia y una necrópolis. La cronología de este yacimiento es amplia y abarca desde el siglo I hasta el VII ${ }^{\mathrm{II}}$.

3. Estudiado el trazado por la actual Comunidad Autónoma riojana en MORENO, Isaac: «Vía romana de Italia a Hispania en La Rioja», El Miliario Extravagante, Anexo 2 (2001), y más recientemente en ALONSO, Carmen y JIMÉNEZ, Javier: «'La Vía romana de Italia a Hispania’ a su paso por la Comunidad Autónoma de La Rioja», Berceo, 154 (2008), pp. 191-226 y en ALONSO, Carmen: La vía romana «De Italia in Hispanias/Item ab Asturica Terracone» a su paso por La Rioja: desarrollo topográfico, evidencias estructurales y modelo constructivo, (Tesis doctoral), UNED, 2015.

4. De época Augustea se conservan uno en Alfaro del 6 a. C. (HeRnÁNDEZ et al., 1999, 255-257) y otro en Calahorra del $9 / 8$ a. C. (CASTILLO Y ESPINOSA, 1995-1997,102). Junto a la desembocadura del Leza, en Agoncillo, están enterrados tres de diferentes emperadores: de Probo del año 263 (CIL II 4.881; ERRioja 75), Carino de entre julio del 283 y enero de 284 (CIL 4.882; ERRioja 76) y un tercero perteneciente a un emperador galo (CIL 4.880; ERRioja 77). Dentro del valle del Najerilla, en Arenzana de Abajo, se halló uno de Claudio del año 43/44 (AE 1997, 915; HEp 7497; EsPINOSA 1994, 139; EsPINOSA \& CASTILLO 1995-1997,106) y otro de Claudio II (268-270) o de Tácito (275-276) encontrado en Tricio (CIL II 4879; ERRioja 74; HEp 10419; GovanTES, 185).

5. Así se ha podido hacer en la vía 34 De Hispania in Aequitania (Itin. Ant. 453.4-456.5) en su tramo entre Veleia (Iruña de Oca, Álava) y Virovesca (Briviesca, Brugos) (GARcíA et al., 2010, 140-142)

6. «Nagera iuxta viam publicam» y «duas sernas ante Formiella ad illam lacunam quas findit illa calzada integras per eorum términos» (CANTERA, 1991, doc. 13, 24 y 27)

7. «latus stratam que ex Tricio pergit ad Naiera», fechado el 25 de febrero del 1036 (García, 2010, doc. LXXV.1, 300)

8. «una vinea tapiata in Alesonciello, latus calçada» y «latus vinea de domno Apparicio: de alia pars, calzata» fechado en el 1102 (GARCíA, 2010, doc. CLIV.az.1, 530).

9. «Et in Castaniares una divisa et uno ero iuxta calzata» fechado el ll de noviembre del 1084 (GARCía, 2010, CXXXVII.[a].1, 446).

10. «Alia terra inter Granione et Villa Farta, latus calzata», sin fecha (GARCíA, 2010, doc. CXXXII.c.1, 435), aunque se especula con que pudiera ser inscrito en el becerro hacia el $1085<$ http://www.ehu.eus/galicano/idig8\&l=es\&cro=0 $>$, (consultado el 15/04/2019).

11. La domus conserva parte de un impluvium de $3.5 \mathrm{~m}$ de lado, el tablinium, varias habitaciones y la parte trasera de la casa. La potencia de algunos de sus muros hace pensar en la posibilitad de que pudieran soportar una planta superior. La zona de elaboración de vino cuenta con todas las estancias: zona de maquinaria de la prensa, plataforma 
El estudio de Parpalinas es muy interesante porque el recinto eclesial albergó, al menos a partir de finales del siglo VI, una cripta funeraria con un sarcófago de un aristócrata con un inequívoco deseo de ser recordado ${ }^{12}$. Demuestra que hubo un grupo de familias de terratenientes que mantuvieron los modos de vida romanos durante el periodo visigodo y que tenían una capacidad inversora que les permitía poner en marcha iglesias en los ámbitos rurales teniendo un activo papel en la cristianización del valle del Ebro.

El sarcófago de Parpalinas, encontrado en los años 70. estaba compuesto de una caja trapezoidal y una cubierta de sección semicircular. El féretro tenía una decoración mediante dobles semicírculos con cuatro en la parte de arriba, otros cuatro en la parte inferior y uno de mayor tamaño en la cabecera y en los pies. La tapa también estuvo decorada de una manera parecida con semicírculos enfrentados a cuatro arcos de los partía bandas rectangulares. La cronología propuesta se sitúa entre los siglos $\mathrm{V}_{\text {y VI }}$. Se trata de un ejemplar único en La Rioja y que, para Urbano Espinosa, fue una pieza de importación ${ }^{14}$.

Para buscar paralelos hay que desplazarse hacia el oeste, hacia la actual provincia de Burgos y en el entorno de Briviesca, la antigua Virovesca. En Tubilla de Agua se localizaron más de 50 fragmentos con la misma decoración e incluyen cubiertas de sección semicircular. Así mismo, también han aparecido ejemplos en Valdelateja, Pesquera de Ebro, Ubierna, Huermeces, Poza de Sal, La Pedraja, Salas de Bureba, Pino de Bureba, Hermosilla de Bureba, Rojas, Quintanabureba y Oña ${ }^{15}$. El problema es que se hallaron descontextualizados.

La excavación de Santa María de los Godos (Trespaderme, Burgos), situada a los pies del castro de Tejada, tiene en planta un mausoleo abovedado con un inicio situado en el siglo $\mathrm{V}$ y en cuyo interior se encontraron sarcófagos con decoración incisa con motivos circulares y semicirculare ${ }^{16}$. Por otro lado, se vincula este tipo

de prensado, lagar y bodega. (Espinosa, 2011a, 189-191). La iglesia posee tres fases: un primitivo centro eclesial de fundación privada datado en el siglo V o principios del VI, un segundo templo de mayores dimensiones con ábside de herradura y cripta funeraria que entró en servicio a finales de la sexta centuria y, por último, un hogar plenomedieval (ESPINOSA, 2006a, 305-322).

12. El sarcófago, tras su descubrimiento, fue partido en múltiples trozos. En el Museo de la Romanización de Calahorra se guarda parte de la cubierta mientras que el Ayuntamiento de Ocón conserva parte de la bañera. Agradezco al profesor Espinosa la información sobre la decoración, su actual situación y su amabilidad al atender cuantas dudas le he planteado. Una aproximación al sarcófago en PASCUAL, 1997, 293-300.

13. EsPINOSA, 2003, 94-95.

14. El resto de sarcófago tardoantiguos descubiertos en La Rioja comparten la peculiaridad de no tener decoración y de cubrirse con tapas a doble vertiente o planas. Una excepción es la lauda musiva de Ursicinus, localizada en la necrópolis de la Azucarera. Por todo ello, Espinosa piensa que se trata de una pieza de importación (EsPINOSA, 2003, 94 y 2011, 59 y SALES, 2012, 327-353).

15. Comparten la característica de tener una bañera de planta trapezoidal y decoración geométrica incisa con motivos de círculos concéntricos, semicírculos, líneas horizontales, ultrasemicírculos y líneas oblicuas y/o verticales en los extremos. Así mismo, pese a aparecer descontextualizados, se encuentran junto a ermitas que posteriormente fueron consideradas como de origen tardoantiguo (CAMPILlo y RAMíreZ, 1984, 210-212 y Sales, 2012, 125-126).

16. Los decorados con motivos geométricos se les considera tardoantiguos o de tradición tardoantigua (LECANDA, 2015, 651-657 y 687-692). 
de estilo decorativo con estelas funerarias alavesas con el mundo tardoantiguo de la zona francesa de Aquitania de los siglos $\mathrm{V} \mathrm{y} \mathrm{VI}^{17}$.

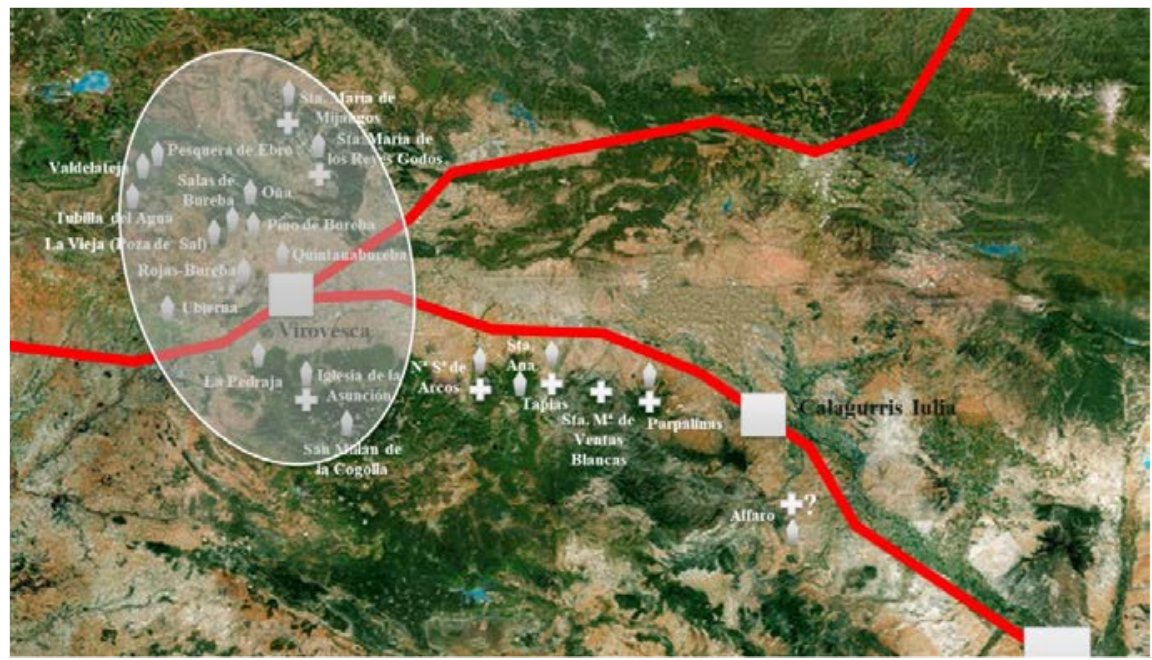

FIGURA. 1. FOCO DE PRODUCCIÓN DE LOS SARCÓFAGOS CON DECORACIÓN INCISA, VÍAS DE COMUNICACIÓN PRINCIPALES Y TEMPLOS CON NECRÓPOLIS TARDORROMANOS EN LA RIOJA. FUENTE: ELABORACIÓN PROPIA/GOOGLE EARTH

El sarcófago de Parpalinas fue producido en esta zona que gira en torno a la antigua civitas de Virovesca (Briviesca), lugar donde se juntaban las calzadas 34 y I/32, bajo la numeración de Saavedra, del Itinerario de Antonino. El féretro recorrió la vía del Ebro y atravesó Libia (Herramelluri), Tritium Magallum (Tricio), Vareia (barrio de Varea, Logroño) y, antes de llegar a la actual Calahorra, se desvió hacia el establecimiento rural parpalinense. Así mismo, la arteria De Hispania in Aequitania pudo servir para que las influencias aquitanas llegasen al este de la provincia de Burgos donde se ubicaría el taller o los talleres donde se fabricaban los ataúdes.

\section{II.2. UNA CONEXIÓN ENTRE EL EBRO Y LA MESETA: EL NAJERILLA COMO VÍA DE PENETRACIÓN}

En la comunidad autónoma de La Rioja, la conexión entre el Ebro y la Meseta se desarrollaba gracias a siete valles trasversales que nacen en el Sistema Ibérico: los del Tirón. el Oja, el Najerilla, el Iregua, el Leza, el Cidacos y el Alhama por

17. Sobre la decoración geométrica realizada con motivos circulares, Lecanda escribe «Tanto Schlunk como Palol señalan sus vínculos con la escuela aquitana, y más recientemente Azkárate y García Camino han vinculado distintas piezas arqueológicas -especialmente estelas funerarias- procedentes de la cercana Llanada Alavesa, con este tipo de decoración, con el mundo aquitano tardorromano, entre los siglos $\mathrm{V}$ y VI d.n.e.» (Ib., 652) 
los que se trazaron vías de carácter secundario en época romana ${ }^{\mathrm{I} 8}$. En el valle del Najerilla, en época antigua, se desarrolló una vía entre Tritium Magallum (Tricio) y el entorno de Nova Augusta (Lara de los Infantes, Burgos) con conexión con la capital conventual de Clunia (Peñalba del Castro, Burgos) ${ }^{19}$.

En la sierra de la Demanda, ha existido una actividad minera con vetas de cobre, hierro plomo y, posiblemente, oro sostenida en el tiempo, especialmente a partir del siglo XVI. Sin embargo, fueron explotados desde, al menos, la época prerromana ${ }^{20}$ para obtener material para la acuñación de moneda bajo las cecas de titiakos, (Tricio o el término de El Villar, Bobadilla), letaisama (¿Ledesma de la Cogolla?) y sekisamos (Cerro Cividad, Canales de la Sierra) ${ }^{21}$. En época romana se ha estimado la existencia de seis minas ${ }^{22}$ y la salida natural de los productos era el Najerilla.

Los hornos de los complejos alfareros de Tricio se extendieron por su entorno más cercano (Bezares o Arenzana de Arriba) y, en época más tardía, llegaron hasta Berceo, Badarán, Cañas o Baños del Río Tobía. En total, se ha estimado que este foco de producción najerense pudo estar en funcionamiento 450 años y sus productos llegaron a ser comercializados a gran parte de la península, el norte de África, Italia, la actual Francia y las Islas Británicas ${ }^{23}$.

Esta comercialización influyó sobre los alfares que surgieron en la Meseta. Los testimonios más antiguos están en Uxama Argaela (El Burgo de Osma, Soria) donde los motivos decorativos se asemejan a los empleados en los talleres tritienses. Se ha propuesto que los centros sorianos dependieran en un primer momento de los riojanos o que alfareros formados en el entorno najerense se instalasen en el entorno de El Burgo de Osma. Con todo, la conexión entre ambas zonas es evidente y se producía a través de la unión de Uxama con Clunia y de esta con el foco tritiense a través del valle del Najerilla ${ }^{24}$.

El mercado de la capital cluniense estuvo inundado por la sigillata de los talleres tritienses desde el siglo II hasta mediados del III cuando los procedentes de los alfares del Arlanza comenzaron a ser mayoritarios ${ }^{25}$. Este nuevo foco produc-

18. De esta manera se han investigado relaciones con Numancia desde Graccurris (ROMERA, 2012, 274-284), Calagurris lulia Nassica (Pascual \& Pascual, 1984, 109-111) y Vareia (EsPINOSA, 1994, 137-144) con Numancia. La primera de ellas, además, cuenta con un testimonio epigráfico: un exvoto a los Lares Viales (CIL II 2987; ILER 584; ERRioja 3 ).

19. Calonge, 2019, 47-69.

20. En declaraciones del profesor Urbano Espinosa recogida por la edición digital del Diario La Rioja: «El foco minero lo explotación los celtíberos, sobre todo los arévacos. En mi opinión, ello explica que los arévacos fueran capaces de sostener durante más de 20 años de confrontación militar con Roma. Todo ello les proporcionó armas y riquezas para la producción. Luego, Pompeyo favorece a los berones porque habían luchado a su favor y se desarrolla la minería». Fuente: <www.larioja.com/pgo60529/prensa/noticias/Sociedad/200605/29/RIO-SUBARTICLE-058.html>, (consultado el 12/04/2019)

21. Para Titiakos: BDHesp, Mon. 58, consulta 13-04-2019; para Letaisama: BDHesp, Mon. 68, consulta 13-04-2019; y para Sekisamos: BDHesp, Mon. 69, consulta 13-04-2019).

22. AYLLón, 2015, 120-121.

23. Junto a los mercados internacionales ya mencionados, destaca especialmente el hecho de que en Hispania eran productos muy apreciados en el valle del Ebro, la Lusitania y la Bética (GARABITO, 1978, 577-586).

24. ROMERO \& ROMERO, 2016, 308-313.

25. F. Tuset y J. Buxeda realizaron un estudio sobre el consumo de sigilata hispánica avanzada dentro de Clunia (TUSET \& BUXEDA, 1995, 355-363) 
tivo se explica gracias al acceso a vetas de arcilla de gran calidad, la existencia de combustible gracias a las superficies boscosas del entorno y los diferentes cursos de agua de la región ${ }^{26}$. Se han descubierto parte de dos complejos en el término de Cantarrillón (Mambrilla de Lara) ${ }^{27}$ y bajo la colegiata de San Cosme y San Damián de Covarrubias ${ }^{28}$. El uso del segundo estilo decorativo de la Mayet, mediante combinaciones de grandes círculos y semicírculos, de los centros alfareros riojanos se constata también en los restos de moldes y de piezas encontradas en la zona del Arlanza.

La conexión entre el Najerilla y la Meseta también queda probada gracias a los testimonios epigráficos. Tritium Magallum ejerció una influencia clara sobre la zona del medio y bajo valle ${ }^{29}$. Sin embargo, el conjunto de seis inscripciones de Canales de Sierra no sigue los estándares de los conjuntos del Ebro, sino que se asemejan más a los testimonios aparecidos en el entorno de Lara de los Infantes ${ }^{30}$ pese a que, geográficamente, el Najerilla desagua en el Iberus.

En época medieval, la zona del Najerilla siguió siendo una zona activa económicamente tal y como evidencian los restos de una estación siderúrgica encontrada en el entorno del santuario de Nuestra Señora de Valvanera y que fue datada por Carbono I4 a finales del siglo VIII. Avala un dinamismo económico previa a la repoblación castellana llevada a cabo en la centuria siguiente ${ }^{3 \mathrm{I}}$.

Las tropas cristianas y musulmanas usaron la vía del Najerilla como punto de penetración. A principios del siglo X, Canales de la Sierra fue destruida por parte del ejército musulmán y esto conllevó la concesión por parte de Fernán González de un fuero a este enclave. Sin embargo, la campaña mejor documentada en esta zona fue la llevada a cabo en el año Iooz por Almanzor. Partió de Córdoba en mayo y pasó por Clunia, Salas de los Infantes y, utilizando el valle del río Pedroso y el paso de Canales, llegó al valle alto del Najerilla por el que descendió para incendiar el monasterio de San Millán de la Cogolla ${ }^{32}$ que ya se estaba configurando como uno de los más importantes centros económicos, sociales y religiosos del valle del Ebro.

En el año 2004, se dieron a conocer los resultados de la investigación sobre los muros de la iglesia de San Millán de la Cogolla de Suso. En lo que Luis Caballero Zoreda denominó como «etapa II Mozárabe. Fase IIB» se descubrieron las

26. Pradales \& Gómez, 2003, 84-85

27. Durante unas obras llevadas a cabo en la N-234, se practicaron intervenciones arqueológicas donde se exhumaron cinco hornos que produjeron terra sigillata hispánica tardía lisa y decorada con el segundo estilo de Mayet (Pérez, 2014, 163-164).

28. En las excavaciones llevadas a cabo en el templo, se encontraron los restos de una estructura de combustión, estancias auxiliares de los hornos, un pórtico y un vertedero. Entre la cultura material destacan los objetos usados por los alfareros y los moldes para la fabricación de terra sigillata lisa y decorada con el segundo estilo (PÉREZ, 2014, 10-163)

29. El profesor Urbano Espinosa relacionaba los testimonios epigráficos encontrados en Tricio con los hallados en la zona de San Millán de la Cogolla y Estollo (ESPINOSA, 1986, 12)

30. ESPINOSA, 1986, 12-13.

31. MADROÑERO, 1985, 20-31.

32. Castellanos, $2003,137-140$. 
evidencias de un incendio entre las primeras fases del edificio antes de las sucesivas reformas y ampliaciones de época mozárabe. El autor maneja, con las dudas razonables, que las fechas de las cenizas encontradas puedan ser coincidentes con el ataque musulmán porque, poco después, se produjo la restauración bajo los auspicios del monarca Sancho III «el Mayor» (IO04-IO35) ${ }^{33}$.

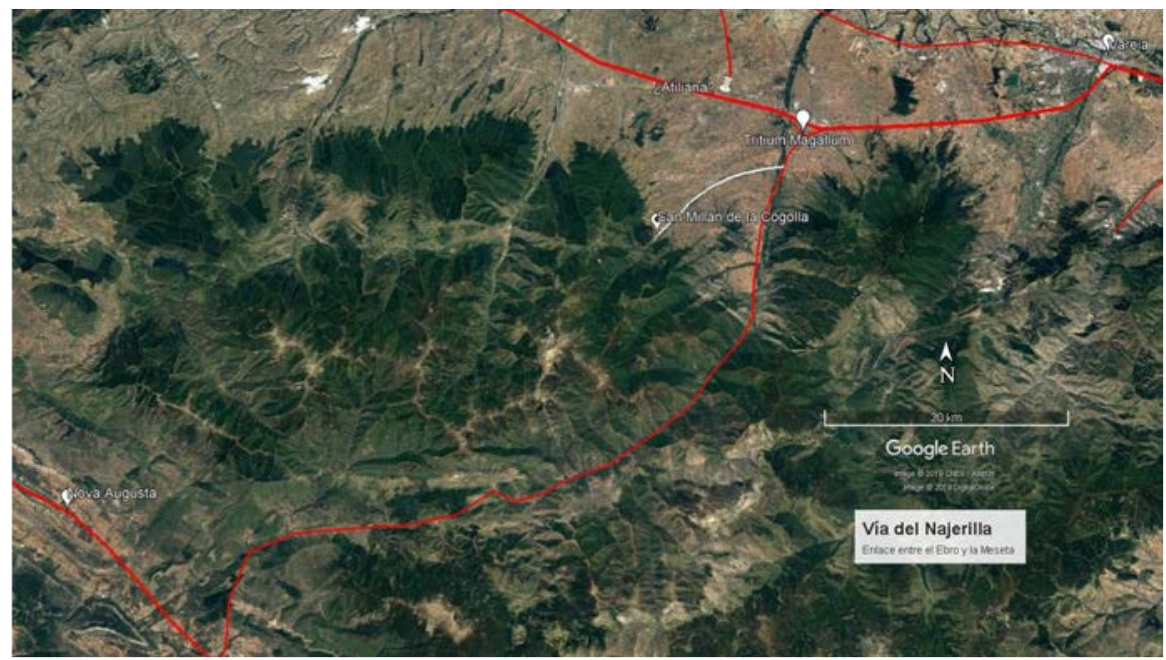

FIGURA. 2. VÍA ROMANA DEL NAJERILLA. FUENTE: ELABORACIÓN PROPIA/GOOGLE EARTH

La documentación medieval recopilada en el archivo de Santa María La Real, el libro-becerro de San Millán de la Cogolla o del santuario de $\mathrm{N}^{\mathrm{a}} \mathrm{S}^{\mathrm{a}}$ de Valvanera recogen testimonios de diferentes vías entre Nájera y el entorno de Anguiano. De esta manera, se puede reconstruir su trazado saliendo por el sur de Tricio atravesando el término municipal najerino para cruzar el río a la altura de Mahave ${ }^{34}$. Continuaba por Baños de Río Tobía ${ }^{35}$, Bobadilla ${ }^{36}$ y Anguiano ${ }^{37}$. No hay más información hasta Canales de la Sierra cuando se menciona otra vía que salía en dirección a Huerta de Arriba, ya en la provincia de Burgos $^{3}$. Así mismo, se han conservado infraestructuras sobre el arroyo Toba dentro del término municipal

33. Caballero, 2004, 42-43.

34. En un documento del Becerro Galicano de San Millán de la Cogolla y fechado el 17 de febrero del 1050 se habla de una propiedad «in via Mahabe, latus flumen» (GARCíA, 2010, doc. LXVI.1, 285-286)

35. En documentos fechados en el 1020 del registro documental del monasterio de Valvanera (GARCíA, 2010, doc. 1. 17-18) y en otro del 1086 del Becerro Galicano (GARCíA, 2010, CCXXX.e.1, 832).

36. Con documentos del Becerro Galicano de los años 1010 (GARCíA, 2010, doc. LXI.1, 277), 1085 (GARCíA, 2010 , doc. CXXXI.c.1, 424), 1086 (GArCíA, 2010, doc. CXXXI.b.3, 423) y 1104 (GArCíA, 2010, doc. CXXXI.d.1., 432), este último aporta la información de que la vía localizada en el término de Bobadilla provenía desde Nájera. A estos se puede añadir otro fechado en el 1074 del archivo de Santa María La Real (CANTERA, 1991, doc. 19, 37-38).

37. En un testimonio del año 1014 del Becerro Galicano (GARCíA, 2010, doc. LXIV.1, 282-283) con la presencia del término via maiore lo que podría evidenciar una mayor relevancia. Hay otras referencias en 1054 (CANTERA, 1991, doc. 13, 28-29), 1079 (GARCíA, 2010, doc. 109, 105-106) y 1081 (GARCíA, 2010, doc.134, 127-128).

38. Fechado en el 1083 y localizado en el Becerro Galicano (GARCíA, 2010, doc. CCCXXIII.1, 1053-1054). 
de Canales: una alcantarilla que regulaba su caudal y de un puente que estaba al servicio de la vía y se orientaba hacia la localidad ${ }^{39}$. La cañada real de Santa Coloma, tras recorrer el interfluvio entre el Iregua y el Najerilla, enlazaba con este último valle en Viniegra de Abajo alejándose hacia el sur del cauce para dejar atrás los meandros encajados. En Villavelayo, regresaba al curso del río y continuaba hacia Canales y Huerta de Arriba ${ }^{40}$. No diferiría mucho del trazado de la antigua vía.

En el lado burgalés, aprovechaba el valle del Tejero/Urría pasando a los pies de la ermita de la Vega (Huerta de Abajo) ${ }^{41}$ y junto al castro romanizada de La Cabeza ${ }^{42}$. Dentro de la cuenca del Pedroso, viraba al sur buscando el centro prerromano de El Castro (Castrovido/Salas de los Infantes) dejando al este la atalaya bajoimperial de Cabeza de San Vicente ${ }^{43}$. Por último, en Salas de los Infantes se han documentado restos del pavimento de una calzada de cronología romana ${ }^{44}$.

La cuenca del Najerilla y la del Arlanza y sus correspondientes tributarios, ponían en comunicaciones algunos de los centros monásticos más importantes de la zona como Santa María La Real, San Millán de la Cogolla, Nuestra Señora de Valvanera, San Pedro de Arlanza y Santo Domingo de Silos por lo que esta vía era un importante camino en el plano religioso, económico y social ${ }^{45}$.

\section{II.3. EL CRUCE DEL EBRO Y EL ENTRAMADO VIARIO A PARTIR DE VAREIA (VAREA, LOGROÑO)}

Vareia llegó a alcanzar un dinamismo económico al tratarse del último puerto fluvial del $\mathrm{Ebro}^{46}$. De esa ciudad partía una vía de carácter secundario que continuaba paralela al curso del río recorriendo la zona norte de la actual Comunidad Autónoma de La Rioja para enlazar mediante un doble bypass con el paso natural

39. El puente tiene unas medias de $8.30 \mathrm{~m}$ de longitud, una altura de $3.15 \mathrm{~m}$ y una anchura que varía entre los 3.50 y los $4.75 \mathrm{~m}$. Su método de construcción se basa en sillarejo y hormigón. La alcantarilla tenía $9.80 \mathrm{~m}$ de longitud, 1.80 $m$ de anchura y $2 \mathrm{~m}$ de altura y estaba ejecutado de una manera muy similar (ARRUE \& MOYA, 1998, 335-337).

40. Gobierno de La Rioja, 2015, 15.

41. Según Julio Escalona, se trata de un yacimiento militar romano vinculado con la vía y a la necesidad de establecer tropas para su control y apoyar a la población del entorno (Escalona, 1995, 199). Juan Antonio Abasolo y Rosario García aportaron, además, la descripción de un edificio monumental con restos suntuarios como fustes o basas de columnas (Abasolo \& García, 1980, 55-56).

42. EsCALONA, 1995, 172-173 y 196)

43. El yacimiento de San Vicente se ha interpretado como un establecimiento para labores defensivas. Tiene una pequeña extensión de 50 × 30 metros y, en superficie, se encontraron restos constructivos, cerámica y escorias (ABAsOlo \& GARCíA, 1980, 74).

44. Código IACYL 09-330-0004-06 recogido en el PGOU de Salas de los Infantes. Catálogo arqueológicopaleontológico. Septiembre de 2009.

45. El mismo acceso al monasterio de la San Millán de la Cogolla en el valle del Cárdenas fue magnificado en e Becerro Galiano. A modo de ejemplo, en un documento del fechado el 14 de mayo del 929 se hace mención en Berceo a una «via publica» (GARCíA, 2010, doc. LXIV.1, 199-200) y, en la misma localidad, pero en el 1105 a «strata» (GARCíA, 2010, doc. IV.b.5, 134) y, muy cerca del cenobio, aparece otra vez la voz «strata» fechado en el 12 de diciembre del 1071 (GARcía, 2010, LXLIX.1, 352-353).

46. Plinio, Nat. His., III-3-14. 
de las Conchas de Haro por un lado y con los Montes Obarenses por otro empleando el puente del Priorato (Cihuri, La Rioja) ${ }^{47}$.

La vía, además, gozaba de una privilegiada situación puesto que empalmaba en el actual término municipal de Fuenmayor con otra calzada que provenía de Tritium Magallum (Tricio) y que continuaba hasta el meandro de «El Cortijo» (Logroño ${ }^{48}$ donde se producía en paso sobre el río Ebro ${ }^{49}$ y continuaba hacia el noreste por Oion (Álava) y Viana (Navarra). En este último enclave, además, se unía con una de las arterias principales del territorio vascón que comunicaba la Vareia Berona con la ciudad de Iacca (Jaca, Aragón) atravesando de oeste a este la Comunidad Foral ${ }^{50}$.

El paso sobre el Ebro se producía gracias al puente de Mantible, una de las infraestructuras más controvertidas del valle del Ebro. Se trata de un paso pétreo de I64 metros de longitud, 5 metros de anchura, siete arcos, seis aliviaderos, un perfil en «lomo de asno» y un sistema de sustentación mediante pilares, tajamares en ángulo y espolón. Su característico perfil se podría explicar debido a la diferencia de alturas entre los márgenes del río. En los estudios de Martín Bueno y Moya Valgañón se hablaba de una cronología de época antonina ${ }^{5 \mathrm{I}}$ coincidente con algunos de los miliarios localizados en la calzada Vareia Berona - Iacca ${ }^{52}$. Además, hay que tener en cuenta que un perfil como el que se encuentra en esta infraestructura también era empleada en época romana ${ }^{53}$ aunque su plenitud se alcanzó en el medievo.

En el año 2004, el profesor Moreno Gallo atribuyó, con la debida prudencia, la construcción del puente a la reina Muniadona «la Mayor» (995-I066), esposa del Sancho III el Mayor debido a las semejanzas estructurales y de método de construcción con el puente de Puente la Reina ${ }^{54}$. La planificación y ejecución de una infraestructura de tal calibre y su posterior mantenimiento era muy costoso

47. Santos y Calonge, 2018, 205-229.

48. Esta vía fue propuesta por Urbano Espinosa y debe su nombre al topónimo «Galiana» que se encuentra en Fuenmayor. Servía para poder sacar las producciones tritienses hacia los territorios vascones y, más allá hacia la Galia (Espinosa, 1994, 143).

49. En algún punto en Assa se produciría la unión de esta vía con el inicio de la calzada entre un empalme de la Vareia berona y lacca (Jaca, Aragón) y con otra de carácter secundario que remontaba la orilla izquierda del Ebro. Testimonio de esta unión, se localizó un epígrafe a los Lares Quadriviales (ELORZA, 1967, 160, n 77).

50. Daba a conocer por Arias Bonet $(1965,181-187)$ en 1965 como una unión entre la actual Jaca y el entorno de Vareia (Varea, Logroño) atravesando de oeste a este Navarra. ARMENDÁRIZ Y VELAZA $(2006,121-124)$ dieron a conocer varios miliarios de esta calzada y afinaron más su trazado.

51. Martín y MOYA, 1972, 165-172.

52. Miliarios de Gallipienzo $\left(E N, 132, n^{\circ} 18\right)$ del que no se conoce la fecha exactamente su año de colocación, aunque sí que es de época de Adriano y el de Oteiza $\left(A E, 1974, n^{\circ} 412\right)$ y una cronología de entre el 10/12/132 y el o9/12/133. Ahora bien, también hay testimonios epigráficos de época de Flavio Severo (01/05/305-25/07/306) localizado en Javier (EN, 136, $n^{\circ} 32 ;$ ILER, 1996) y del reinado de Constantino I (307-337) encontrado en Arellano (ARMENDÁRIZ Y VELAZA, 2006, 109-126).

53. De esta manera está la parte romana conservada del puente sobre el Lima (Ponte de Lima, Portugal) consistentes en cinco arcos de diferentes luces y altura creando un ligero perfil alomado (DURÁN, 2005, 226-230), el tramo I del puente romano de Mérida sobre el Guadiana con un perfil con una pendiente de 2.7\% (DURÁN, 2001, 238-252) o el Pont Julien sobre el río Coulon en Francia (DURÁN, 2005, 38, 56, 61-63, 66-67, 84, 208 y 328).

54. MORENO, 2004, 66-72. 
y, si la tesis del profesor Moreno Gallo es la acertada, hay que añadir un contexto de guerra en la región que no se terminó de estabilizar hasta la toma definitiva de Calahorra en el ı045. A menos de io km, se levantó el puente románico de San Juan en Logroño que debía estar en servicio para el año I095, fecha de la promulgación del Fuero de Logroño por parte del rey Alfonso VI y que se encontraba fortificado apenas medio siglo después cuando los privilegios fueron confirmados por Alfonso VII en el II4655. La fecha de construcción exacta de ambos puentes es problemática, aunque sí se sabe con seguridad cuando el Camino de Santiago fue desviado por el actual territorio riojano. Las crónicas Silense y Najerense recogen cómo fue Sancho Ill «el mayor» el que hizo que la Ruta Jacobea pasase al sur del Ebro de manera oficial tras la retirada musulmana de la región y su posterior estabilización que garantizaba la seguridad de los peregrinos ${ }^{56}$.

Como en los otros casos, la vía fue utilizada para poder llevar a cabo expediciones de conquista, castigo o saqueo. La más temprana se recogió en la Crónica de Alfonso III donde se habla de cómo Alfonso I en el 739 o en el 740 marchó con sus huestes hacia el Ebro pasando por Miranda de Ebro y saqueando Ábalos, en la margen izquierda del río, y pasando a la zona sur en algún punto de Briones, continuó la campaña hasta Cenicero, momento en el que se beneficiaría de la existencia de la antigua calzada romana ${ }^{57}$.

En el 796, los musulmanes iniciaron operaciones para poder reconquistar Calahorra. Tras la toma de la ciudad, se lanzó a la caballería a saquear los campos y los enclaves hasta el Cantábrico. Es de suponer que utilizaron la antigua calzada De Italia in Hispanias hasta Vareia (Logroño) y, más allá, la calzada paralela al Ebro ${ }^{58}$. Esta misma ruta debieron utilizar las tropas que fueron derrotadas por los cristianos en las «Puertas de Arganzón» (Paso de las Conchas de Haro) un lustro después ${ }^{59}$.

En la documentación medieval también quedó fosilizado parte del trazado de esta vía romana, especialmente interesante en el vadeo del río Najerilla en la actual localidad de Torremontalbo y que se recoge en un documento fechado en el año I054 y procedente del archivo de Santa María La Real de Nájera ${ }^{60}$. Más al oeste, en San Asensio, aparecen los topónimos de Aquilonis ${ }^{61}$ y Davalillo ${ }^{62}$ que se

55. Para más información sobre las menciones del puente de San Juan de Logroño vid. ARRúE-MoYA, 1998, 784-785.

56. Crónica Najerense, III.1 y SANTOS Coco, 1921, 63.18-64.2.

57. En versión Ovetense: «(...) Mirandam, Ravendecam, Carbonariam, Abeica, Brunes, Cinisaria, Alesanco (...)» y en la Rotense: «Miranda, Ravendeca, Carbonarica, Abeica, Cinasaria et Alesanco» (UBIETO, 1971, 36-37).

58. Recogida por el cronista musulmán Ibn Hayyan en sus escritos sobre Alhakan I y Abdarrahman II. Almuqtabis II-1, año 180 (Alı MAKKI-CORRIENTE CóRdoba, 2001, 24-25).

59. Almuqtabis II-1, año 185 (Alı MAKKI-Corriente Córdoba, 2001, 36-37)

6o. «de occidente rivus qui vadit in Monte Albo» (CANTERA, 1991, 13.10)

61. El documento se fecha el 26 de enero del 1078 y procede del Becerro Galicano (GARCíA, 2010, CXXV). Se identifica con el actual topónimo de Aguillones, junto al Ebro y en el norte de San Asensio.

62. El cerro de Davalillo se sitúa al norte de San Asensio. Actualmente está coronado por un castillo, los restos de un poblado, una necrópolis medieval y una ermita del siglo XVI. En el documento citado (vid. supra 41), ya se cita un vicus Davalellum, es decir, un enclave rural. También se han documentado la presencia del entramado viario en Davalillo en textos recogidos en el libro-becerro de San Millán y fechados en el 1086 (GARCíA, 2010, CCXXX) y en 1096 (Ib., CCCXVI) 
encuentran unidas mediante una vía. Este último es particularmente interesante porque se habla la donación del Monasterio de la Ascensión, situado junto a este lugar, en un documento con una cronología muy temprana: el 28 de marzo del 81 $3^{63}$.

Gracias a todos estos datos, se puede decir que esta vía de carácter secundario salía por el oeste de Logroño, continuaba por el cerro de El Cortijo, atravesaba los términos municipales de Fuenmayor, Cenicero y San Asensio donde comenzaba su separación del curso del Ebro. Entre Briones y Ollauri, se producía una bifurcación: un ramal viraba al norte rumbo a Haro atravesando Gimileo y el otro continuaba al sur de Ollauri y al norte de Rodezno siguiendo por Casalarreina, Cihuri, donde se conserva el puente del Priorato ${ }^{64}$, y Sajazarra ${ }^{65}$ rumbo a los montes Obarenses.

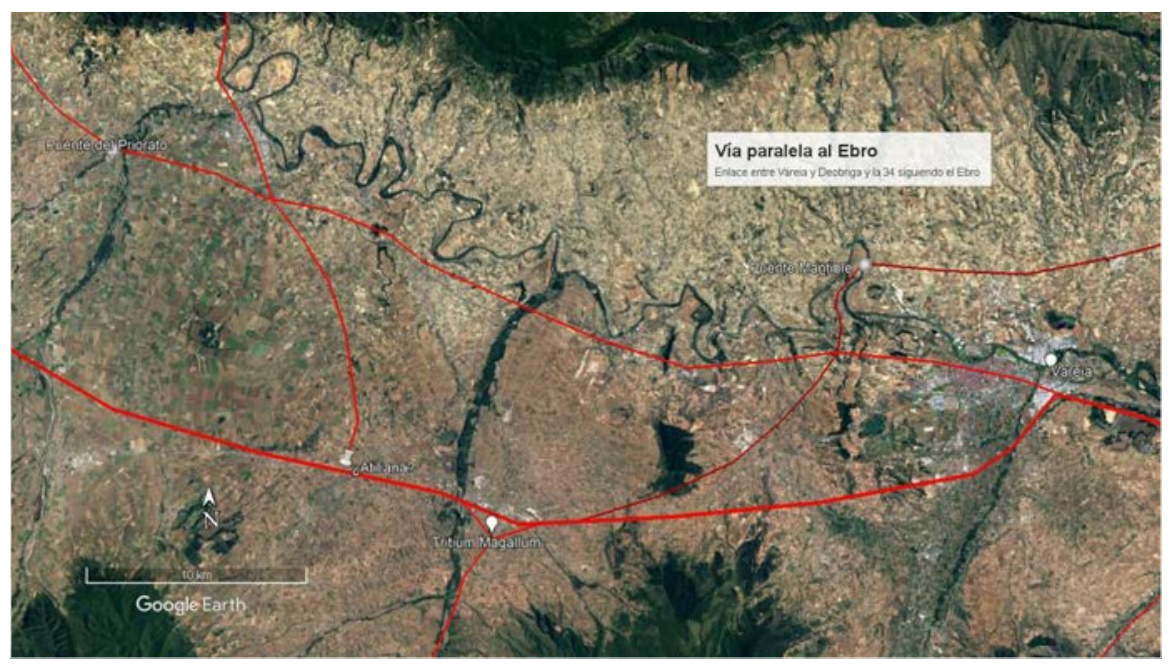

FIGURA. 3. ENTRAMADO VIARIO EN EL NORTE DE LA RIOJA. FUENTE: ELABORACIÓN PROPIA/GOOGLE EARTH

\section{GEOGRAFÍA DE LA CRISTIANIZACIÓN}

Contando únicamente con los datos aportados por la arqueología sobre edificios religiosos y necrópolis de carácter cristiano, se puede rastrear la supervivencia del entramado viario romano. Especialmente interesantes son las estructuras defensivas que contaron en su interior o en sus proximidades con una iglesia: Bilibio (Haro, La Rioja), Buradón (Labastida, Álava) y el castillo de Viguera (La Rioja).

63. Donación llevada cabo por parte de Elvira y su vástago Álvaro en favor de Santa María de Quijera recogida en el Becerro Galicano (GARCíA, 2010, CCXLI).

64. Puente de dos arcos, uno de ellos reconstruido en el siglo XIII; un aliviadero y un pilar con tajamar. La longitud total es de 27.83 metros, una anchura que va desde los 3.83 y los $4.42 \mathrm{~m}$ y una cronología estimada de entre los siglos I Y II (ARRUE y MOYA, 1998, 85 y 246-251).

65. Se conservan los restos de un sencillo puente sobre el río Mardancho con una longitud de $5.15 \mathrm{~m}$, una anchura que varía entre los 3.05 y los $3.30 \mathrm{~m}$ y una altura de $1.80 \mathrm{~m}$ (ARRUE y MOYA, 1998, 272-273. 
Con la pérdida de capacidad dinamizadora de las ciudades, fueron surgiendo diferentes castros fortificados en los límites de los antiguos territorios adscritos a ellas o controlados directamente por estos entornos urbanos. Su interpretación no es sencilla, aunque comparten una cronología de inicio en torno al siglo V. Se han querido ver cómo fundaciones de carácter público para articular el territorio desde el punto de vista militar, político, fiscal y religioso. Geográficamente se extienden esencialmente por el alto valle del Ebro, especialmente entre las provincias de Burgos y La Rioja. El modelo de enclave incluía un centro fortificado y un edificio de carácter religioso. Uno de los mejor conocidos es la fortificación de Tejada (Trespaderme, Burgos), que ocupa una superficie aproximada de I.5 hectáreas en su parte fortificada. A sus pies, se consagró el templo de Santa María de los Reyes Godos ${ }^{66}$.

Misma cronología y modelo de poblamiento tiene el recinto de Buradón. En la cima del cerro se observa la existencia de una posible fortificación, un depósito de agua y una torre, aunque se le presupone una cronología más tardía, posiblemente plenomedieval ${ }^{67}$. En la ladera sur de la colina, se ha podido investigar parte de un poblado asentado en terrazas realizadas con potentes muros. Los edificios son domésticos e incluyen espacios de almacenaje y cocinado, aunque se desconoce si estaba protegido por un recinto amurallado. El asentamiento se inicia en el siglo IV y continúa hasta el siglo $\mathrm{VI}^{68}$. El templo, con una posible advocación a San Mamés y construido en las últimas fases del enclave rural, tiene unas medidas de I7X5 metros y contaba con una nave rectangular, una cabeza tripartita y una posible piscina bautismal de planta cuadrada en los pies. Sufrió varias modificaciones entre los siglos V y IX y también se excavó un cementerio que estaba vinculado con el edificio cristiano ${ }^{69}$.

Muy cerca, al otro lado del Ebro y protegiendo la margen derecha del paso natural de las «Conchas de Haro», se encuentran los «Riscos de Bilibio» que, según la tradición, fue el lugar donde habitaba San Felices, maestro de San Millán. Recientemente, Jose María Tejado ha dado a conocer los resultados de varias intervenciones arqueológicas llevadas a cabo en la zona superior donde se construyó una fortificación. Este recinto se encontraba amurallado, tenía hasta cuatro torres de vigilancia y de comunicación. Así mismo cree probable la presencia de un faro terrestre. La cronología de los restos arrancan en torno al año mil, aunque Tejado también reconoce que esta población, producto de una reforma, pudo arrasar los restos de uno anterior de origen tardoantiguo ${ }^{70}$.

Una evolución parecida tuvo una iglesia rupestre localizada en la ladera sur de los riscos: el conocido como «templo de Paceta». En origen, tenía dos habitaciones

66. Iglesia con planta basilical, cabeza tripartita, altar y mausoleo. También se localizó una necrópolis en las inmediaciones (LECANDA, 2015, 687-692).

67. SAGREDO, 2006, 233-236.

68. Martínez y Cepeda, 1994, 54-56.

69. Martínez y Cepeda, 1994, 48-53.

70. TEJADO, 2018, 83-95. 
separadas por un muro interior y debió servir a la fortaleza. Pudo también albergar los restos de San Felices. Sufrió varias remodelaciones hasta el traslado del santo a San Millán de la Cogolla a finales del siglo $\mathrm{XI}^{71}$. Este templo se une a otros que fueron surgiendo durante el Bajo Imperio. Eran primitivos focos de cristianización lejos de las grandes ciudades para poder tener mayor libertad en el ejercicio del nuevo credo $^{72}$.

Estos recintos fortificados controlaban el paso natural de las Conchas de Haro usado en época antigua con el trazado de una vía de carácter secundario que unía Deobriga (Arce-Mirapérez, Miranda de Ebro, Burgos) con el valle del Ebro (vía Vareia-Cihuri) ${ }^{73}$ y con Atiliana (entorno de Azofra, La Rioja) ${ }^{74}$. El acceso a la civitas mirandesa también le proporcionaba una posible labor de vigilancia sobre la calzada Ab Asturica Burdigalam del Itinerario de Antonino y del paso hacia los montes Obarenses, situado al oeste.

Otro ejemplo de fortaleza situada en la margen del territorio de una antigua civitas y que combina un centro amurallado con un templo se localiza Viguera (La Rioja), al sur de Vareia. Se ha teorizado con la posibilidad de que existiera una vía de comunicación de época romana que remontase el valle del Iregua desde la actual Logroño hasta el paso de Piqueras. Por ahora, las intervenciones arqueológicas han podido datar los estratos más antiguos en época visigótica entre el 547 y el $709^{75}$. Sin embargo, los enclaves rurales romanos dentro del ager vareyense debieron estar comunicados con la ciudad por lo que se debió trazar una vía, al menos, hasta las inmediaciones de Viguera ${ }^{76} \mathrm{y}$, más allá tuvo que haber también un camino o sendero hacia el sur, donde se han localizado indicios de poblamiento con el hallazgo de epígrafes ${ }^{77}$. La fortificación de la localidad viguereña controlaba el acceso al interior del valle y vgilaba la antigua calzada principal del Ebro.

71. La sala exterior correspondería con la entrada donde también estaría ubicado un hito religioso. El muro que separa ambas estancias tenía obertura para posibilitar la entrada de luz natural hacia la habitación interior. Tiene una cubierta de realizada con una bóveda ejecutada mediante aproximación de hileras, tres nichos y el altar orientado al este con otro nicho (PASCUAL et al., 2006 725-732)

72. Ejemplos como el eremitorio de Bendigoma en Briñas, el monasterio de San Andrés en Santa Engrancia del Jubera, San Pedro en Torrecilla, San Esteban en Viguera, el primitivo templo rupestre junto al Monasterio de $N^{a} S^{a}$ de Vico o el cenobio dúplice de Santa Lucía en Ocón (PAscual et al., 2006,725-737)

73. Vid supra nota 46

74. Investigada por Carmen Alonso, esta vía ponía en comunicación las calzadas De Italia in Hispanias que recorría el valle del Ebro con la Ab Asturica Burdigalam que provenía de la llanada alavesa. Gracias a la toponimia, la distribución del poblamiento rural y la pervivencia de elementos de origen vasco que ejemplifican una repoblación con contingentes venidos desde el norte en varios despoblados de la zona de Haro, esta autora puede reconstruir un recorrido de más de $23 \mathrm{~km}$ (ALONSO, 2018, 180-185).

75. TEJADO, 2018, 98.

76. En la documentación de ratificación de los privilegios del monasterio de San Martín de Albelda, aparece el término de Marcuero que, según Urbano Espinosa, provendría de los rituales que en tiempos antiguos se hacían entorno a las aras sagradas dedicadas a Mercurio. Sería una prueba de la posible vía del Iregua en la zona de Albelda (ESPINOSA, 2011b, 26)

77. En el valle del Iregua se han encontrado testimonios epigráficos en: Alberite (ERRioja, 12 y 13), Montemediano de Cameros (ERRioja, 51), Nieva de Cameros (ERRioja, 52, 53, 54 y 55), Ortigosa de Cameros (ERRioja, 56 y 57), Pradillo de Cameros (ERRioja, 58), El Rasillo de Cameros (ERRioja, 59, 60 y 61), Villoslada de Cameros (ERRioja, 62) o San Andrés de Cameros, término municipal de Lumbreras (AE 1997, 923; HEp 7, 1997, 586). 
Las intervenciones arqueológicas llevadas a cabo por José María Tejado estiman para el castillo de Viguera ${ }^{78}$ unas I8 hectáreas de superficie. Se encuentra enclavado en un lugar de fácil defensa con paredes verticales de Ioo $\mathrm{m}$ de altura y un único acceso probable en la zona sur. Por ahora, se han podido documentar una iglesia fechada entre los siglos VII y VIII, un sistema de aljibes de agua tallados en la roca de casi 6 metros de diámetro, el acceso y, entre la cultura material, destaca la presencia de materiales bajoimperiales y de una trompa de cerámica usada para labores de comunicación y alarma ${ }^{79}$.

La ubicación de las iglesias ${ }^{80}$ también tiene relación con el entramado viario de origen romano. Dejando a un lado las que se ubicaron en las antiguas civitates, las que fueron surgiendo en el ámbito rural ${ }^{8 \mathrm{I}}$ siguen un patrón de asentamiento que las aleja del trazado de las calzadas principales, aunque las mantiene con una conexión directa con estas. Especialmente interesante es el caso del valle del Bajo Iregua, entre los actuales términos municipales de Albelda de Iregua y de Nalda.

Durante el siglo XX, se exhumaron dos iglesias de planta cruciforme gracias a los trabajos llevados a cabo por Blas Taracena ${ }^{82}$ y Urbano Espinosa ${ }^{83}$. Esta última muy interesante porque albergaba en su interior una cripta funeraria donde se depositaron varios enterramientos entre los que destacaba uno en un sarcófago pétreo con tapa a doble vertiente. El profesor Espinosa piensa que la función de esta cámara era secundaria con respecto al significado religioso del propio templo pero que le otorgaba gran parte de su razón de ser. Estas inhumaciones, especialmente la del féretro pétreo, indican una posible fundación privada del templo

78. Se trata de uno de los diversos sistemas defensivos que se han localizado en las inmediaciones y que fueron construidos durante siglos. En palabras del Dr. Tejado «Pensamos que esta concentración de diferentes tipos de fortificaciones (castillo de Castañares de las Cuevas, fortificación de San Esteban, Peña Castillo y torre de vigilancia de Peña Candil, puestos de control del paso del barranco de los Infiernos y de Las Guardias, etc.). Todas ellas responden en nuestra opinión al deseo, prolongado en el tiempo, del intento de control de la clausura baja del río Iregua» $(2018,99)$

79. TEJADO, 2018, 99-103.

80. En una misiva firmada por el Papa Hilario, afirma que honorati y possessores de las ciudades de Turiaso (Tarazona), Cascantum (Cascante), Calagurri (Calahorra), Vareia (Varea-Logroño), Tritium (Tricio), Libia (Herramelluri) y Virovesca (Briviesca) le había escrito directamente a Roma para poder defender la acción del obispo Silvano de Calahorra que había sido denunciado por el Prelado de Tarragona (ESPINOSA, 1984, 275 y BARENAS, 2016, 159-160). Gracias a este documento se puede decir que en estas ciudades y sus proximidades había comunidades cristianas asentadas a mediados del siglo $\checkmark$ al que podemos sumar un templo en Graccurris gracias a las evidencias arqueológicas localizadas en el yacimiento de las Eras de San Martín (MARTíneZ, 1993, 25-26). Así mismo, hay testimonios epigráficos de temática cristiano como el epígrafe funerario de Tateca en Tricio (ERRioja, 38) o la lauda musiva sepulcral de Ursicinus localizado en Alfaro (ERRioja, 2)

81. Para más información sobre los templos del entorno de Berceo, la ermita de Santo Domingo en Cervera de Río Alhama, la Ermita de Santa Ana en Entrena, Santa María de Ventas Blancas en Lagunilla del Jubera, la iglesia de Levia en la actual Leiva, el Martyrium de Santa Coloma, la iglesia de El Salvador en Tirgo o los templos de San Esteban y San Martín en Viguera, entre otros, ver SaLES, 2012, 327-354.

82. La primera iglesia la descubrió el profesor Blas Taracena entre 1925 y 1926 con una estancia central de $6.50 \times$ 4 metros a la que se adosaron otras cuatro por lo que el templo alcanzaba $13.53 \times 10.37 \mathrm{~m}$. Destacaba especialmente la existencia de techumbres de tegulae, la presencia de una necrópolis y una cronología del siglo VII para la construcción del edificio eclesial (ESPINOSA, 20116, 109-113).

83. Situada a unos $25-30$ al sur de la excavada medio siglo antes, con unas medidas muy similares de $14.40 \mathrm{~m}$ de largo y 10.20 y una planta que tiene a ser cruciforme. Tiene un cuerpo central que tenía la función de nave central, la estancia de acceso situada al norte, el ábside al este, la habitación del sur con una función problemática y una cripta funeraria con contra-ábside construido al oeste y en la que se encontró un sarcófago pétreo (ESPINOSA, 2011b, 37-63). 
por parte de una familia aristocrática que patrocinó su construcción y lo dotó de rentas para su mantenimiento siguiendo las actas conciliares ${ }^{84}$.

Y no es el único testimonio de construcción de carácter cristiano en la zona. A $2.6 \mathrm{~km}$ al sur del conjunto de Las Tapias, se encontraba un conjunto de varios templos pertenecientes al antiguo monasterio de San Pantaleón (Nalda) que son mencionados en la carta fundacional de San Martín de Albelda. Blas Taracena, en los años 20, ya expuso la existencia de grandes habitaciones con cerámica de construcción de tradición romana. Para el profesor Espinosa, los dos centros de Las Tapias y este nuevo localizado en Nalda estaban plenamente conformados y en funcionamiento en el siglo VIl y ambos comparten un patrón de asentamiento claro: ubicación en terrenos altos y áridos, lo que dificultaba su cultivo y próximos a la vía secundaria del Iregua ${ }^{85}$.

Hay una estrecha relación entre estos dos conjuntos y las cuevas artificiales del entorno. San Martín de Albelda tuvo un acentuado carácter semirupestre, a los pies de la Peña Salagón y es probable que se ubicase en ese lugar un grupo eremítico anterior al siglo X. En primer lugar, es una zona donde ya se ha podido comprobar la existencia de los conjuntos monacales de Las Tapias y de San Pantaleón de época visigoda. En segundo lugar, durante el derribo en 1978 de la iglesia del siglo XVII se comprobó que se asentaba en muros de piedra profundos, aunque no se realizaron labores arqueológicas que pudieran aportar una cronología a los mismos. Eso sí, a la entrada de este edificio eclesial se conservaban capiteles visigodos que lamentablemente se perdieron. En tercer lugar, una hornacina del conjunto de cuevas, donde se ubicó San Martín, conserva un arco de herradura. La elección de este lugar para poder levantar un nuevo monasterio en tiempos de Sancho Garcés pudo deberse al mantenimiento de uno anterior que hibiera sobrevivido a la etapa de dominación musulmana tal y como habían hecho las iglesias que formaban parte del conjunto de San Pantaleón ${ }^{86}$. Son indicios más que probatorios de un cenobio visigodo en esa zona y que era el tercero en un espacio articulado por la antigua vía romana del Iregua.

Los conjuntos de cuevas artificiales que se pueden encontrar por toda el área geográfica del Ebro Medio siguen también patrones de asentamiento claros:

84. Tal y como expresan las actas del Concilio de Lérida (can. III) del 546, el II de Braga (can. V) del 572 o el IV de Toledo (can. XXIII) del 633. Los obispos sólo acabaron admitiendo iglesias que se encontrasen jurídicamente reconocidas por sus diócesis y exigían una correcta dote para las mismas. Los fundadores privados, por su parte, fueron obteniendo más atribuciones, pero se sometieron, al menos nominalmente, a la autoridad de los prelados (SOTOMAYOR, 2004, 530-531; BARENAS, 2015, 785-787).

85. Se presupone la existencia de entre 3 y 4 templos que se encontraban bajo la advocación del cenobio de San Pantaleón que, a su vez, se debió constituir en un momento similar al conjunto de Tapias a finales del siglo VI. Estas iglesias aun estaban activas cuando San Martín de Albelda se creó y se le dotó de un territorio adscrito en el siglo X (UBIETO, 1981, 9-12) EsPINOSA, 2011b, 148-150).

86. Urbano Espinosa afirma que es necesario la labor de una profunda investigación de carácter arqueológico en la zona para determinar las características del fenómeno eremítico tardoantiguo en el lugar donde se ubicaría posterior el monasterio de San Martín de Albelda, aunque los indicios que expone son más que suficientes para hablar de un cenobio visigótico a la sombre de la Peña Salagón (EsPINOSA, 2011b, 152-157). 
lugares de fácil defensa y difícil acceso que se suelen excavar en promontorios erosionados por los tramos medios de los ríos. Se sitúan alejados de las grandes vías de comunicación, pero siguen sus trazados. Funcionalmente, los grandes conjuntos albergarían población civil incluyendo espacios litúrgicos; mientras que también existieron abrigos que se usaron como espacios eremíticos. Urbano Espinosa destaca especialmente las cuevas del entorno de Nájera y San Millán de la Cogolla en el valle del Najerilla, las que se encuentran entre Nalda y Albelda en el Iregua, las de Leza y de Jubera en el Leza, las del Cidacos entre Autol y Santa Eulalia y las del Alhama en los entornos de Inestrillas y Cervera del Río Alhama ${ }^{87}$.

María del Pilar Pascual hace un catálogo de las cuevas en el actual territorio riojano $^{88}$ y apunta a que se ubicaban en los escarpes que se alzan sobre los caminos secundarios que recorrían los valles tributarios del Ebro, con una orientación para aprovechar la luz solar y cerca de las fuentes de riqueza ${ }^{89}$.

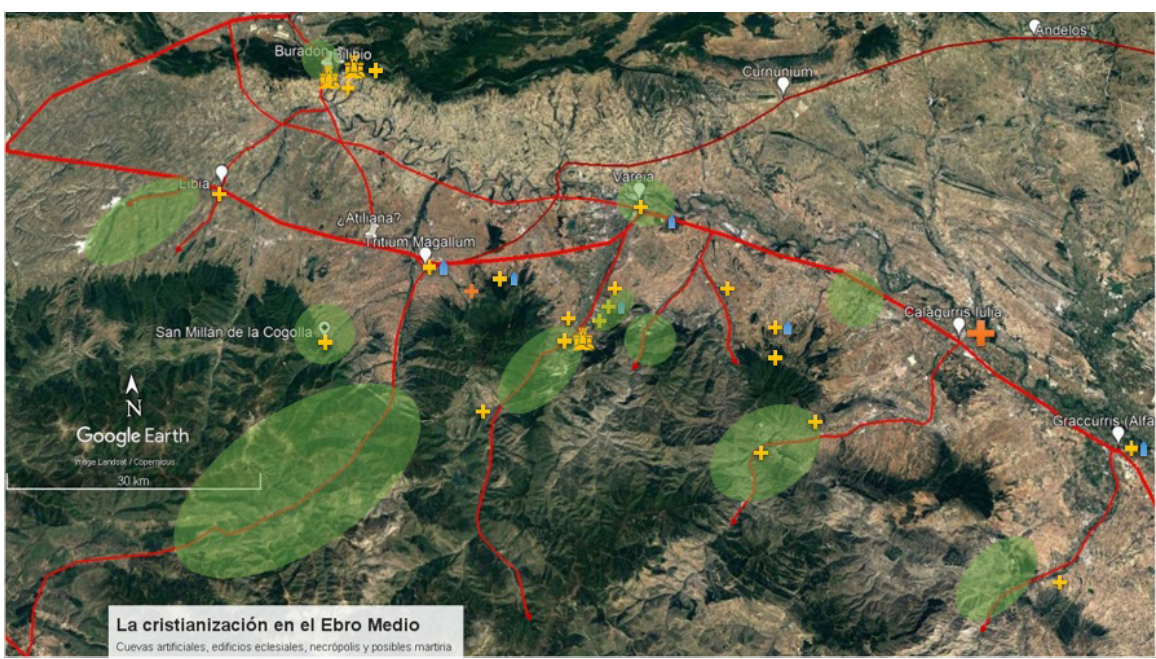

FIGURA. 4. LA CRISTIANIZACIÓN EN EL EBRO MEDIO. FUENTE: ELABORACIÓN PROPIA/GOOGLE EARTH

87. El profesor Espinosa piensa que la ocupación intensiva y la excavación de nuevas cuevas se produjo a partir del estallido del fenómeno de la Bagauda y su posterior represión por parte del poder imperial, es decir, a partir de la segunda mitad del siglo V (2006, 81-83).

88. Gracias a la toponimia y a la prospección, recoge los palomares de los valles del Iregua, Leza, Jubera, Cidacos, Alhama, Queiles y del mismo Ebro. Se centra especialmente en la figura de los palomares (PASCUAL, 1999, 87-116).

89. Un ejemplo es la ubicación de las cuevas en el Jubera que se construyeron junto a las minas. En las cavidades y en sus entornos se desarrolló un poblamiento en época visigoda con la presencia de canteras de molinos y algunos despoblados (PASCUAL, 1999, 117) 


\section{CONCLUSIONES}

Las vías romanas fueron una de las principales herencias que la administración de la Ciudad Eterna dejó en todo el territorio que tuvo bajo su control. Una red que se mantuvo y sufrió obras de reparaciones para posibilitar que pudieran seguir en servicio. Su papel en el auge económico, en el control militar, en el desarrollo de la burocracia y como vehículo de romanización está fuera de toda duda. El actual territorio riojano lograba tener una conexión directa con el Mediterráneo, el ámbito galo, la dinámica región del Noroeste y en interior peninsular. Con la caída política de Roma en el 476, la pervivencia de su cultura, sus costumbres y su sistema social continuó pese a la sustitución del antiguo poder imperial por los reinos germánicos, especialmente el visigodo.

La gran problemática del estudio de las vías romanas dentro de la actual Comunidad de La Rioja radica en la escasez de testimonios epigráficos más allá de la vía del Ebro que fue recogida en el Itinerario de Antonino y del ara a los Lares Viales en la calzada del Alhama. De ahí que el estudio del patrón de asentamiento del poblamiento romano, el comercio o la influencia de los entornos urbanos, entre otras variables, son esenciales para poder investigar el trazado de las infraestructuras de transporte de carácter secundario. Del mismo modo, las menciones recogidas en la documentación medieval tampoco son heterogéneas ya que se suelen circunscribir al empleo del término «vía». Las unidades de población que fueron surgiendo en esta época son esenciales para plantear la supervivencia de estas estructuras en el medievo.

Esta continuidad se observa en el aprovechamiento del viario romano durante los primeros siglos de la época medieval. Fueron empleadas para de nuevo para asegurar el control militar con los nuevos actores que se configuraron dentro de las campañas entre cristianos y musulmanes siendo Alfonso I y Almanzor dos ejemplos para la vía paralela al Ebro y para la del Najerilla respectivamente. Esta última, además, se configuró también como una Cañada Real y sirvió como vía de comunicación de los principales monasterios de la región: San Millán de la Cogolla, Nuestra Señora de Valvanera, Santa María de San Salvador de Cañas, San Pedro de Arlanza y Santo Domingo de Silos. Estos, al margen de su poder religioso, eran también centros políticos, económicos y sociales de primer nivel, especialmente en el caso del cenobio emilianense.

Fueron también motores económicos que sirvieron para el comercio de la cerámica de los tardíos talleres alfareros del Najerilla y sus tributarios, de bienes de lujo como los sarcófagos de los talleres localizados en el este de la provincia de Burgos, como posteriores cañadas reales para el transporte de ganados o como salida de los productos de las canteras del Leza-Jubera o de las minas del entorno del Moncayo. Siguieron articulando el territorio y los recintos fortificados que se construyeron en los límites de los antiguos territorios de las civitates romanas buscaban su vigilancia y control. Pero también sirvieron como base para el patrón 
de asentamiento del poblamiento rural, base económica de las aristocracias que patrocinaron la construcción de templos y cenobios que sirvieron para posibilitar la extensión del cristianismo. En definitiva, siguieron manteniendo su funcionalidad inalterada y contribuyeron a la evolución histórica del área de estudio propuesta.

La relación de estos centros religiosos, que constituyeron las bases para la cristianización de los entornos rurales, con las vías de comunicación es clara. Una de las explicaciones es por su mismo lugar de construcción que se produjo en función de quiénes fueron sus patronos. Si estos eran las familias aristocráticas y grandes propietarias, se asentaban en sus propias tierras compartiendo de esta manera el patrón de asentamiento de las explotaciones rurales. En este caso pueden adscribirse los casos del edificio eclesial con advocación a Santa María en Parpalinas (Ocón), Santa María de Rute (Ventas Blancas, Lagunilla del Jubera), el conjunto de Tapias (Albelda) o los orígenes de la actual ermita de Santa Ana (Entrena). Las que fueron levantadas dentro de los recintos fortificados encuentran su conexión con el entramado viario de la región gracias a la posición de estos enclaves. Su origen parece corresponder a una iniciativa pública de control de determinados lugares considerados como estratégicos como son el acceso al valle del alto Iregua y la vigilancia de la calzada del Ebro desde Viguera o el paso de las Conchas de Haro que se desarrolla a los pies de Bilibio y Buradón. No hay que olvidar tampoco las iglesias que fueron promovidas por los centros episcopales de los que actualmente se desconoce su ubicación ${ }^{90}$.

Así mismo, las vías de comunicación continuaron conservando un aura de sacralidad por lo que hubo necrópolis que se desarrollaron junto a ellas. La de la Azucarera en Alfaro, lugar de descubrimiento de varios sarcófagos y de la conocida como lauda sepulcral de Ursicinus (actualmente en el Museo Arqueológico Nacional y del siglo V) y de indicios de un edificio de carácter religioso; o los enterramientos localizados en Igay (Logroño) de cronología visigoda junto con los restos de un edificio de época romana que fue reutilizada como posible centro religioso ${ }^{9 \mathrm{I}}$. I9 27. Ambos ejemplos se localizan al lado del trazado de la vía De Italia in Hispanias. Además, el ejemplo logroñés cumple con los criterios enunciados en su día por Ripoll: un cerro elevado cerca de una fuente de agua y de una vía de comunicación ${ }^{92}$.

Otra de las claves que explican la supervivencia de alguna de las vías de comunicación de origen romano durante el periodo medieval fue el mantenimiento de población de las zonas por donde pasaban y a las ciudades a las que servían. El mejor ejemplo es la calzada del Ebro recogida en el Itinerario de Antonino. En el tramo riojano, su trazado cruzaba los territorios adscritos administrativamente a las civitates de Graccurris (Alfaro), Calagurris Iulia (Calahorra), Vareia (Logroño), Tritium Magallum (Tricio) y Libia (Herramelluri). La sede del obispado y la única entidad

90. Para más información sobre las iglesias de origen tardoantiguo ver SALES, 2012, 327-353.

91. Alonso y JiMÉnEZ, 2014, 19-27.

92. RIPOLL, 1989, 396-402 y ALONSO Y JIMÉNEZ, 2014, 25. 
urbana que se dotó de defensas pétreas con una potente muralla fue Calahorra y siguió conservando su preeminencia durante gran parte de los siglos siguientes a los siglos posteriores al ocaso romano. Tricio sufrió una potente decadencia, pero, en este caso, fue Nájera la que heredo la potencia económica, demográfica y política de la zona estando apenas a dos kilómetros al norte del antiguo centro del foco alfarero. Alfaro, Varea y Herramelluri apenas conservaron población, pero siguieron sirviéndose de la red caminera que heredaron.

Por último, tampoco hay que olvidar el propio contexto histórico que se desarrolló en el actual territorio riojano tras el ocaso del poder político romano en el área de estudio propuesta. Dejando atrás los traumáticos sucesos de la bagauda, en la zona del Ebro Medio se observa un florecimiento de los enclaves rurales bajo el nuevo cetro visigodo. Sin embargo, las excavaciones llevadas a cabo en el viario romano no han dado indicios de arreglos o mantenimientos de los antiguos trazados viarios romanos que siguieron en servicio ${ }^{93}$. La sustitución de los monarcas germánicos por el poder musulmán a partir del siglo Vlll y la inestabilidad provocada por las frecuentes razzias y guerras entre estos y los reinos cristianos que se sucedieron hasta la definitiva toma de Nájera y de Calahorra, ambas en el siglo XI, no hizo posible o viable la construcción de nuevos caminos o vías debido a este contexto conflictivo. Además de que hay que cuestionarse la necesidad de estas nuevas infraestructuras habida cuenta de que el entramado viario romano hacia muy difícil la planificación de nuevos senderos ya que la mayor parte de las mismas ya había sido planificado en época romana. Hoy en día, las modernas LR-II3 y BU-825, partes de la N-232, AP-68 y A-I2 y partes de la N-232 y AP-68 son los ejemplos actuales de las vías del Najerilla, del Ebro y la Paralela al Ebro respectivamente.

93. Entre el reacondicionamiento que se produjo en el siglo III o IV y nuevas intervenciones en el siglo XVI, no hubo grandes remodelaciones entre ambas épocas (ALONSO Y JIMÉNEZ, 2014, 17-19 y ALONSO, 2015, 551-554). 


\section{BIBLIOGRAFÍA}

Abasolo, José Antonio y García, Rosario: Carta arqueológica de la provincia de Burgos. Partido judicial de Salas de los Infantes, Burgos, Diputación Provincial, I980.

Alí Makkı, M. y Corriente, F. (200I), Ibn Hayyan. Crónica de los emires Alhakam I Abdarrahman II entre los años 796 y 847 (Almuqtabis II-I), Zaragoza, Instituto de Estudios Islámicos y del Oriente Próximo.

Alonso, Carmen: La vía romana «De Italia in Hispanias/Item ab Asturica Terracone» a su paso por La Rioja: desarrollo topográfico, evidencias estructurales y modelo constructivo, (Tesis doctoral), UNED, 2015.

Alonso, Carmen, «Sobre las huellas de Roma: la caminería en La Rioja en época tardoantigua» en Tejado, José María (coord.), Vislumbrando la Tardoantigüedad. Una mirada desde la arqueología, Logroño, Instituto de Estudios Riojanos, 2018, I69-196.

Alonso, Carmen y Jıménez, Javier: «La «Vía romana de Italia a Hispania» a su paso por la Comunidad Autónoma de La Rioja», Berceo, I54 (2008), pp. I9I-226.

Alonso, Carmen y Jiménez, Javier: «A las puertas de Vareia: el Camino Viejo de Logroño a Calahorra y el conjunto arqueológico de Igay (Logroño, La Rioja)» , Berceo, I66 (2014), pp. 7-29.

ARMENDÁRIZ, Javier y VelazA Javier: «Dos miliarios romanos en Arellano: contribución al estudio de las comunicaciones viarias en época romana en Navarra», Trabajos de Arqueología Navarra I9 (2006), pp. I09-I26.

Arrue, Begoña y Moya, José Gabriel: Catálogo de puentes anteriores a I8oo. La Rioja, Logroño, Instituto de Estudios Riojanos, Centro de Estudios y Experimentación de Obras Públicas, Centro de Estudios Históricos de Obras Públicas y Urbanismo y Ministerio de Fomento, I998.

Ayllón, Ruth: Cuevas, bosques y montañas sagradas de Celtiberia (ss. Il a.C.-II d.C.): entre la transformación y el abandono (Tesis doctoral), Barcelona, Universidad de Barcelona, 2015.

BARENAS, Ramón: La articulación eclesiástica del valle medio del Ebro y su área de influencia (ss. III-VIII) (Tesis doctoral) Logroño, Universidad de La Rioja, 2015.

BARENAS, Ramón: «Calahorra y el cisma de la Tarraconense occidental», Kalakorikos 2I (2016), pp. I55-I86.

CABAllero, Luis: «La iglesia de San Millán de la Cogolla de Suso. Lectura de paramentos 2002» , en Gil-DíEz, Ignacio (coord.): Arte medieval en La Rioja: prerrománico y románico. VIII Jornadas de Arte y Patrimonio Regional (Logroño, 29 y 30 de noviembre de 2002), Logroño, Instituto de Estudios Riojanos, 2004, pp. I3-94.

CALONGE, Adrián (20I9), «La vía romana del Najerilla: una introducción a su estudio», Veleia 36 (2019), pp. I83-205.

CAmpillo, Jacinto y Ramírez, M.M.: «Descubrimiento de una necrópolis altomedieval en Tubilla del Agua (Burgos)», Kobie. Serie de paleoantropología y ciencias naturales I4 (I984), pp. 207-2I5.

CANTERA, Margarita: Colección documental de Santa María La Real de Nájera. Tomo I (siglos $X-X I V)$, San Sebastián, Eusko Ikaskuntza, I99I.

CAStellanos, Juan: Geoestrategia en la España Musulmana. Las campañas militares de Almanzor, Madrid, Ministerio de Defensa, 2003

CASTillo, María Josefa y Espinosa, Urbano: «Novedades epigráficas en el medio Ebro (La Rioja)», Lucentum I4-I6 (I995-I997), pp. IOI-II2. 
DuRÁN, Manuel: La construcción de puentes romanos en Hispania, Santiago de Compostela, Universidad de Santiago de Compostela, 2005.

Elorza, Juan Carlos: «Ensayo topográfico de epigrafía romana alavesa», Estudios de Arqueología Alavesa 2 (1967), pp. II9-I85.

Escalona, Julio: Transformaciones sociales y organización del espacio en el Alfoz de Lara en la Alta Edad Media (Tesis doctoral), Madrid, Universidad Complutense, I995.

Espinosa, Urbano: Calagurris Iulia, Calahorra, Colegio oficial de Aparejadores y de A.T. de La Rioja y Ayuntamiento de Calahorra, I984.

EsPINOSA, Urbano: Epigrafía romana de La Rioja (ERRioja), Logroño, Instituto de Estudios Riojanos, I986.

EsPinosA, Urbano: «Ordenación territorial», en SESMA, Jesús Ángel (coord. gen.), Historia de la Ciudad de Logroño. Tomo I, Logroño, Ayuntamiento de Logroño e Ibercaja, I994, pp. II5-I46.

Espinosa, Urbano: «El enclave Parpalines de la Vita Sancti Aemiliani; espacio rural y aristocracia en época visigoda», Iberia 6 (2003), pp. 79-Io9.

Espinosa, Urbano: «La iglesia tardoantigua de Parpalinas (Pipaona de Ocón, La Rioja), campaña arqueológica de 2005», en Conde, M.E., González, R. y Egea, A. (Coord.), Espacio y tiempo en la percepción de la antigüedad tardía: homenaje al profesor Antonio González Blanco, «In maturitate aetatis ad prudentiam». Antigüedad y cristianismo 23 (2006a), pp. 309-322.

EsPiNosa, Urbano: «Civitates y territoria en el Ebro Medio: continuidad y cambio durante la Antigüedad Tardía», en Espinosa, Urbano y Castellanos, Santiago (eds.): Comunidades locales y dinámicas de poder en el norte de la Península Ibérica durante la Antigüedad Tardía, Logroño, Universidad de La Rioja, 2006b, pp. 4I-Ioo.

EsPinosA, Urbano: «La villa prolongada en el tiempo. El caso de Parpalinas (Pipaona de Ocón, La Rioja)» en Quirós, Juan Antonio (coord.), Vasconia en la Alta Edad Media, 450I0oo: poderes y comunidades en el norte peninsular, Vitoria, UPV/EHU, 20IIa, pp. I8I-I92.

Espinosa, Urbano: La iglesia de Las Tapias y los monasterios tardoantiguos de Albelda de Iregua y Nalda (La Rioja), Logroño, Universidad de La Rioja, 20 Irb.

Hernández, José Antonio, Ariño, Enrique, Martínez, José Manuel y NúÑEz, Julio: «La presa y el ninfeo del Sotillo (Alfaro, La Rioja): un conjunto monumental en la via De Italia in Hispanias», Zephyrus 52 (1999), pp. 237-258.

Garabito, Tomás: Los alfares romanos riojanos. Producción y comercialización, Madrid, CSIC-Instituto Español de Prehistoria, Servicios de Publicaciones de la Universidad de Valladolid y Diputación provincial de Logroño, 1978.

García, Juan José, Peterson, David, García, Iván y García, Lucía: «Introducción al conocimiento de la viaria romana de la cuenca del Duero a través de la documentación altomedieval» en VV.AA; Las técnicas y la construcción en la ingeniería romana. Actas del congreso de las Obras Públicas Romanas (5. 20Io. Córdoba), Madrid, Fundación de la Ingeniería Técnica de Obras Públicas, 2010, pp. I35-i64.

García, Fernando: El Becerro Galicano de San Millán de la Cogolla, Logroño, Cilengua, 2010. Gobierno de La Rioja: «Caminos de Pastores. Gestión de las vías pecuarias en La Rioja», Páginas de información ambiental 2I (2005), pp. 313-32I

LeCANDA, José Ángel: Estudio arqueológico del Desfiladero de La Horadada: la transición entre la tardorromanidad y la Alta Edad Media (ss. V-X d.n.e.) (Tesis doctoral), Burgos, Universidad de Burgos, 20I5. 
MADROÑERo, Antonio: «Interpretación inicial de los restos de una estación siderúrgica aparecidos en el entorno del santuario de Ntra. Sra. de la Valvanera (Rioja)», Revista Técnica Metalúrica, julio-agosto (I985), pp. 20-3I.

Martín, Manuel y Moya, José Gabriel: «El puente Mantible», Estudios de Arqueología Alavesa 5 (1972), pp. I65-I82.

Martínez, José Manuel «Excavaciones arqueológicas en las Eras de la Cárcel», Estrato 5 (I993), pp. 23-26.

Martínez, Ana y Cepeda, Juan José: «Castro de Buradón» en Baldeón, Amelia y García, Elisa (coords.): Arqueología de Urgencia en Álava. 1989-I993, Vitoria, Diputación Foral de Álava y Museo Arqueológico de Álava, I994, pp. 43-60.

Moreno, Isaac: «¿Es romano el puente Mantible?: el camino de Pamplona a Nájera de Sancho el Mayor», Piedra de Rayo I2 (2004), pp. 66-72.

Moreno, Isaac: «Vía romana de Italia a Hispania en La Rioja» , El Miliario Extravagante, Anexo 2 (200I).

Pascual, María del Pilar «Sobre un fragmento de sarcófago depositado en el museo municipal de Calahorra (La Rioja), Kalakorikos 2 (I997), pp. 293-300.

PASCUAL, María del Pilar: «Columbarios de La Rioja y su distribución geográfica» , Antigüedad $y$ cristianismo I6 (I999), pp. 87-II8.

Pascual, María del Pilar y Pascual, Hilario: Carta arqueológica de La Rioja I. El Cidacos, Calahorra, Amigos de la Historia de Calahorra, I984.

Pascual, María del Pilar, García, Pedro, Cinca, José Luis y Pascual, Hilario: «La cueva de Paceta: Castro Bilibio (La Rioja) ¿Un oratorio rupestre?, Antigüedad y Cristianismo 23 (2006), pp. 719-737.

Pérez, Fernando: «Los centros de producción de la Terra Sigillata Hispánica tardía. Antiguos y nuevos centros, hornos y estructuras asociadas», Oppidum. Cuadernos de Investigación Io (2014), pp. I47-I76.

PradAlEs, David y Gómez, Julio «La arqueología romana en la provincia de Burgos. Orígenes y desarrollo (II)», Boletín de la Institución Fernán González 226 (2003), pp. 6I-85.

Ripoll, Gisela: «Características generales del poblamiento y la arqueología funeraria visigoda en Hispania», Espacio, Tiempo y Forma. Serie I. Prehistoria y Arqueología, 2 (I989), pp. 389-4I8.

ROMERA, Andrés Luis: Conexión con la Meseta desde el Ebro Medio de las vías romanas como base de la mallaterritorial de España (Tesis doctoral), Madrid, Universidad Politécnica de Madrid, 2012.

Romero, María Victoria y Romero, Fernando: «La Sigillata Hispánica de Uxama Argaela y Tritium Magallum. Reflexiones acerca de las relaciones entre ambos centros productores», Anejos a Cuadernos de Prehistoria y Arqueología de la Universidad Autónoma de Madrid 2 (2016), pp. 299-3I4.

SAgredo, Iñaki: Navarra. Castillos que defendieron el Reino. Tomo I. De Laguardia a Foix y del Moncayo al Goierri, Pamplona, Editorial Pamiela, 2006.

SAntos, Fernando: Crónica Silense, Madrid, Junta para la Ampliación de Estudios e Investigaciones Científicas y Centros de Estudios Históricos, I92I.

SANTOS, Juan y CALONGE, Adrián: «El entramado viario romano en el norte de La Rioja: sobre la calzada paralela al Ebro (Logroño-Cihuri)» en CASTIllo, Pepa e IguÁcel, Pilar (eds.): Studia Historica in Honorem Prof. Urbano Espinosa, Logroño, Universidad de La Rioja, 2018, pp. 205-234.

SALES, Jordina: Las construcciones cristianas de la Tarraconensis durante la Antigüedad Tardía. Topografía, arqueología e historia, Barcelona, Universitat de Barcelona, 2012. 
Sотомауов, Manuel: «Las relaciones iglesia urbana-iglesia rural en los concilios hispanoromanos y visigodos» en BlázQuEz, José Manuel y GonZÁlez, Antonino (eds.): Sacralidad y arqueología. Antigüedad y cristianismo 2I (2004), pp. 525-539.

TEjADo, José María: «Fortificaciones militares en el alto valle del Ebro. Tres ejemplos de herramientas de control territorial y social» en TEjADo José María (coord.): Vislumbrando la Tardoantigüedad. Una mirada desde la arqueología, Logroño, Instituto de Estudios Riojanos, 20I8, pp. 73-II6.

Tuset, Francesc y BuxedA, Jaume: «La cerámica Terra Sigillata Hispánica Avanzada (TSHA) de Clunia: segunda mitad del siglo II-siglo III d.C.» en OliveirA, Víctor: Actas del I Congreso de Arqueología Penínsular. Trabalhos de Antropologiae Etnologia, Oporto, Sociedade Portuguesa de Antropología e Etnologia, I995, pp. 355-367.

Ubieto, Antonio: Crónica de Alfonso III, Valencia, Universidad de Valencia, I97I.

Ubieto, Antonio: Cartulario de Albelda, Zaragoza, Anubar Ediciones, I98I.

UвiEto, Antonio: Crónica Najerense, Zaragoza, I985. 

Calidad de Revistas

Científicas Españolas

FECYT |
SERIE III HISTORIA MEDIEVAL

REVISTA DE LA FACULTAD DE GEOGRAFÍA E HISTORIA
AÑO 2020

ISSN: 0214-9745

E-ISSN 2340-1362

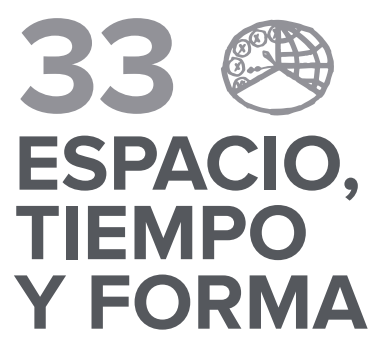

\section{Artículos · Articles}

7 FREDERIC APARISI ROMERO

El cultivo y procesado del lino en el Reino de Valencia (ss. XIII-XVII)

13 ADRIÁN CALONGE MIRANDA

El mantenimiento del entramado viario romano en época medieval en La Rioja. Algunos casos de estudio

\section{Miguel Calleja Puerta}

Notarios públicos entre dos reinos. Apuntes diplomáticos sobre documentos notariales castellanos en el Arquivo Distrital de Braga

\section{Xavier Casassas Canals}

Las 'aqida-s entre los musulmanes castellanos y aragoneses de época mudéjar y morisca: Las 'aqida-s de lbn Abi Zayd Al-Qayrawāni (s. X), Ibn Tümart (s. XII) e Isa de Jebir (s. XV)

\section{ARCADIO DEL CASTILLO}

Sobre el Códice Alcobacense de Vaseo y los Annales Portugalenses Veteres: Continuidad del reino visigodo de Toledo

\section{Paula Castillo}

Las formas de la violencia entre frailes. El testimonio de Fray Ubertino de Casale

\section{María Eugenia Contreras JimÉnEZ}

La memoria del linaje Arias Dávila en la cofradía y hospital de San Cosme y San Damián de Valladolid (siglos XV a XVII)

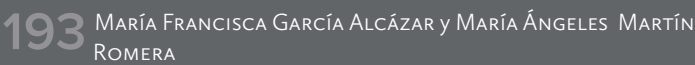
Entre servicio regio y estrategia personal: Los Continos de Valladolid (1480-1525)

\section{César García de Castro Valdés y josé Antonio Valdés
Gallego}

Las inscripciones perdidas de la basílica altomedieval de San Salvador de Oviedo

\section{María José Lop OtÍN}

Hay tal número de clérigos que causa asombro. La clerecía de Toledo a fines de la Edad Media

\section{CORINA LUCHÍA}

Por que los montes de esta villa se conserben, e no se disipen como al presente estan: La regulación de los recursos forestales en la Corona de Castilla (siglos XIV-XVI)
333 María Encarnación Martín López

Las inscripciones medievales del claustro de la catedral de Roda de Isábena (Huesca). Aproximación a su taller lapidario

\section{ISABEL MONTES ROMERO-CAMACHO}

Los archivos catedralicios y su importancia para los estudios prosopográficos. El deán Don Aparicio Sánchez, en el Archivo de la Catedral de Sevilla

\subsection{Gonzalo Oliva Manso}

La moneda en Castilla y León (1265-1284). Alfonso X, un adelantado a su tiempo.

4.73 Mariana Valeria Parma

Entre los signos del cielo y las voces de los hombres: La visión medieval del cielo y su representación apocalíptica

\section{Milagros Plaza Pedroche \\ Los maestres santiaguistas y su designación regia durante el} reinado de Juan I de Trastámara (1379-1390): La legitimación del proceso

521 Juan A. Prieto Sayagués

La profesión de las élites castellanas en los monasterios y conventos durante la Baja Edad Media

\section{EnRIQUe José RuIz PILARES}

La funcionalidad social de los inmuebles urbanos de las élites dirigentes bajomedievales: Reflexiones a partir de un caso de estudio (Jerez de la Frontera, España)

\section{Gilberto SORIANO Calvo}

Influencia de las redes nobiliarias en la expansión cristiana del siglo XII. El caso de Soria

Mohammed S. TawfiQ, AlmudenaArizaArmada, Atef Mansour Mohammad, Ahmed Ameen y Mervat Abd EL-HadyAbdEL-Latif A Historical and Numismatic Study of the Dinars of the Ghaznavid Sultan Mahmūd B. Sabuktakin at Nishapur

653 JOSÉ LUIS DE VILLAR IGLESIAS

Los aspectos económicos en la Batalla por el Magreb entre omeyas y fāțimíes: El control del acceso al oro del Sudán Occidental

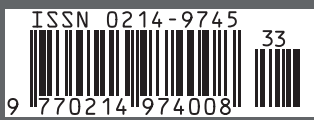




\section{3}

\section{ESPACIO,}

\section{TIEMPO}

Y FORMA

UกED

SERIE III HISTORIA MEDIEVAL

REVISTA DE LA FACULTAD DE GEOGRAFÍA E HISTORIA

\section{Libros · Books}

679 Bello León, Juan Manuel y ORTEgo Rico, Pablo, Los agentes fiscales en la Andalucía Atlántica a finales de la Edad Media: Materiales de trabajo y propuesta de estudio (ANA MARÍA RIVERA MEDINA)

683 Calleja Puerta, Miguel y Domínguez Guerrero, María Luisa (eds.), Escritura, notariado y espacio urbano en la Corona de Castilla y Portugal (siglos XII-XVII) (PALOMA CUENCA MuÑoz)

687 CASADO ALONSO, Hilario (coord.), Comercio, finanzas $y$ fiscalidad en Castilla (siglos XV-XVI) (ANA MARía RIVERA MEdINA)

691 Castro Correa, Ainoa y Rodríguez Sánchez, Manuel, Colección diplomática altomedieval de Galicia II. Documentación en escritura visigótica de la sede lucense (PALOMA CUENCA MUÑOZ)

695 García Fernández, Ernesto, García-Gómez, Ismael, Rodríguez FERNÁNDEZ, José, Urbanismo, patrimonio, riqueza y poder en Vitoria-Gasteiz a fines de la Edad Media e inicios de la Edad Moderna (ENRIQUE CANTERA MONTENEGRO)

699 LADERO QUESADA, Miguel Ángel, Ciudades de la España medieval. Introducción a su estudio (GISELA CORONADO SCHWINDT)

705 LADERo Quesada, Miguel Ángel, Los últimos años de Fernando el Católico 1505-1517 (CARLOS BARQuero GoÑI)

707 Martín GutiérRez, Emilio y Ruiz Pilares, Enrique José, El viñedo en Jerez durante el siglo XV. Un mercado de trabajo en torno al vino (ANa María Rivera MEDINA)

711 MONSALVO ANTÓN, José María, La construcción del poder real en la monarquía castellana (siglos XI-XV) (MARÍA Jesús FUENTE)

715 Pérez Rodríguez, Francisco Javier, Los monasterios del Reino de Galicia entre 1075 y 1540: De la reforma gregoriana a la observante (EnRIQue CANTERA Montenegro)

717 REIXACH SALA, Albert, Finances públiques i mobilitat social a la Catalunya de la Baixa Edat Mitjana. Girona, 1340-1440 (JuLIÁN DONADO VARA)

721 SÁNCHEZ SÁNCHEZ, Xosé M., Iglesia, mentalidad y vida cotidiana en la Compostela medieval (ENRIQUe CANTERA MONTENEGRO)

725 Val Valdivieso, M. ${ }^{a}$ Isabel del, Martín Cea y Juan Carlos, CARVAJAL de La Vega, David (coords.), Expresiones del poder en la Edad Media. Homenaje al profesor Juan Antonio Bonachía Hernando (José RAmón Díaz de DURANA ORTIZ de URBINA) 